\title{
Nonlinear model predictive control of biodiesel production via transesterification of used vegetable oils
}

\author{
Ana S.R. Brásio ${ }^{\mathrm{b}}$, Andrey Romanenko $^{\mathrm{b}}$, João Leal ${ }^{\mathrm{b}}$, Lino O. Santos ${ }^{\mathrm{a}, *}$, \\ Natércia C.P. Fernandes ${ }^{a}$ \\ a CIEPQPF, Department of Chemical Engineering, Faculty of Sciences and Technology, University of Coimbra, 3030-790 Coimbra, Portugal \\ b Ciengis, SA, 3030-199 Coimbra, Portugal
}

\section{A R T I C L E I N F O}

\section{Article history:}

Received 27 March 2013

Received in revised form

24 September 2013

Accepted 25 September 2013

Available online 26 October 2013

\section{Keywords:}

Biodiesel

Transesterification reaction

Nonlinear model predictive control

Modeling

\begin{abstract}
A B S T R A C T
The economic performance of an industrial scale semi-batch reactor for biodiesel production via transesterification of used vegetable oils is investigated by simulation using nonlinear model predictive control (NMPC) technology. The objective is to produce biodiesel compliant to the biodiesel standards at the minimum costs. A first-principle model is formulated to describe the dynamics of the reactor mixture temperature and composition. The feed oil and mixture composition are characterized using a pseudo-component approach, and the thermodynamic properties are estimated from group contribution methods. The dynamic model is used by the NMPC framework to predict the optimal control profiles, where a multiple shooting based dynamic optimization problem is solved at every sampling time. Simulation results with the economic performance of an industrial scale semi-batch reactor are presented for control configurations manipulating the methanol feed flow rate and the heat duty.
\end{abstract}

(c) 2013 Elsevier Ltd. All rights reserved.

\section{Introduction}

The biodiesel production process has received a great deal of attention from both industry and academia. Several literature reviews on the biodiesel resources and production technology are available (e.g., $[1,2])$. The technical aspects of production and of the quality analysis of biodiesel from used cooking oil have been reviewed in [3], the biodiesel production using catalyzed transesterification has been reviewed in [4]. Several works address the process plant design and its economics. Examples of these are the development of a biodiesel production and refining process using rape seed oil in [5], the economic analysis of biodiesel production processes using fresh and waste vegetable oil and supercritical methanol in [6], and the economic assessment of four biodiesel production processes with different levels of complexity in [7].

According to a review of available process technologies [8], the alkali-catalyzed transesterification remains so far one of the main production routes for biodiesel production. Conventional biodiesel process plants involve batch reactors or continuous stirred tank reactors (CSTRs). The use of batch production technology is quite frequent in small and/or medium scale biodiesel companies. This is the case of companies that produce biodiesel from used vegetable oils, such as recycled vegetable cooking oils, where the flexibility

\footnotetext{
* Corresponding author. Tel.: +351 239798 792; fax: +351 239798703.

E-mail address: lino@eq.uc.pt (L.O. Santos).
}

of a plant layout based on batch reactors is a key asset to handle local market raw material fluctuations.

The study of the dynamics and control of the biodiesel production process has also been addressed in various research works. For instance, the dynamics and control of biodiesel production in a CSTR have been investigated in [9]. The mechanistic model of the reactor is formulated assuming a constant holdup. It includes the coolant fluid dynamics, and it uses the kinetic transesterification model of palm oil of [10]. The variation of the overall heat transfer coefficient is modeled as a function of the coolant flow rate and of the stirrer speed. The closed loop simulation results show that a multi-model control strategy outperforms a conventional proportional-integral-derivative (PID) controller because of the nonlinearity of the dynamic system. The design of two control loops has been considered in [9]. In one of the control loops the concentration of fatty acid methyl esters (FAME) is controlled by manipulating the feed rate of the reactant (a mixture with a methanol to triglyceride molar ratio of $6: 1$ ). In the other control loop, the temperature of the reacting mixture is controlled by manipulating the coolant flow rate. Different control system algorithms have been tested for these two control loops [11]. An instantaneous linearization technique is used to extract a linear model from a neural network nonlinear model for a general predictive control (GPC) algorithm. The comparison with the performance of adaptive self-tuning regulators algorithms, favors the application of the predictive algorithm to control the biodiesel reactor production. In [12], a recursive least square algorithm has been applied 
to adapt the settings of the internal model controllers of the same dynamic system. The design and control of a biodiesel production process with phase separation and recycle in the reactor system has been investigated in [13]. The resulting plant-wide control system uses decentralized PID controllers. The reactor dynamics of the soybean oil transesterification with methanol are modeled using the kinetic model of [14].

In [11-13], the biodiesel production is carried out in CSTRs. The problem of optimal control for biodiesel production in a batch reactor to calculate the optimal temperature profile in order to maximize the final concentration of FAME has been addressed in [15]. The reactor model uses the kinetic model of [14]. This work has been extended to the study of the effect of uncertainty in the reactor feed [16], and to solve the optimal problem for both the maximum concentration and minimum time of operation using a two layered optimization strategy [17]. The control of advanced biodiesel production plant designs has been also investigated. Examples of these are the temperature control of a biodiesel microwave reactor [18], and the control of biodiesel production with reactive absorption process technology [19].

In this work nonlinear model predictive control (NMPC) technology based on a first principle model is applied by simulation to control the transesterification reaction in a semi-batch biodiesel reactor. The main control objective is to comply with the final biodiesel product quality specifications while minimizing the consumption of methanol and the use of energy to cool or to heat the reactor mixture. The NMPC controller is seen here as an important contributor to the economic performance of the semi-batch biodiesel reactor. NMPC can be advantageous in processes that exhibit nonlinear behavior in the operating region of interest, with changes in the gains sign, input and/or output multiplicities, and processes where a trajectory needs to be tracked such as in batch and semi-batch processes. The literature available on Model Predictive Control (MPC) is quite vast, with reviews on industrial applications [20], several books [21], and research works in various domains of application [22], to cite but a few. A recent review on the major developments of MPC during the past three decades is given in [23]. The NMPC framework applied in this work, Plantegrity ${ }^{\circledR}$, features a predictive control formulation with a multiple shooting strategy to perform the state predictions [24,25]. This method is also referred to as direct multiple shooting [26,27]. The Plantegrity framework features as well a plant simulator module, and a state and parameter estimator based on the Unscented Kalman Filter (UKF) formulation [28]. The simulator, NMPC, and UKF modules communicate through a database, with data exchange synchronization. There is a computational delay associated with the UKF estimator and NMPC controller calculations that is taken into account in the simulation platform as it would occur in the case of a real implementation. Algorithmic solutions have been proposed to reduce this computational delay (e.g., see [29,27,30-32] and references therein). Several examples of NMPC applied to batch or semi-batch processes can be found in the literature, where different NMPC algorithm variants make use of a first principle dynamic model, such as batch fermentation processes (e.g., [33]), timber drying [34], batch or semi-batch polymerization reactors (e.g., [35-38]), batch reactive distillation column (e.g., [39]), temperature control of an industrial semi-batch pilot-plant reactor [40], and of an industrial batch polymerization reactor [27].

The feed oil mass composition used in the present work is taken from [41]. It is made of a mixture of $10 \%$ of Jatropha curcas oil with $90 \%$ of waste food oil. A pseudo-triglyceride approach [42] is applied to characterize the feed oil and reactor mixture. This is done to simplify the description and modeling of the transesterification system, because it would be too complex or even impossible to characterize quantitatively its dynamics in terms of all possible combinations of different fatty acid chains present in the feed oil.
This approach has been used, for instance, by $[43,44]$ in the context of phase equilibrium studies of oils. In [5] the same approach has been applied in the development of a biodiesel production and refining process using rape seed oil. One emphasizes that this same approach is commonly used in the modeling of the transesterification reaction kinetics.

The paper is organized as follows. The semi-batch reactor model is presented in Section 2, along with the methodology to compute the thermodynamic properties of the reactor mixture. The problem statement and the nonlinear model predictive control (NMPC) framework description are given in Section 3. Operating conditions for the semi-batch reactor for biodiesel production, using one ton of used vegetable oil, and the dynamic profiles are presented in Section 4. First, open loop profiles in batch mode of operation are presented for operating conditions similar to those described by [41]. Then, results of the application by simulation of NMPC are given for control configurations where the methanol feed flow rate and the heat duty are manipulated to comply with the final biodiesel product specification at a minimum cost.

\section{Reactor model}

The transesterification reaction of triglycerides (TG) with methanol yields esters of fatty acids (E) and glycerol (G), and can be described by three reaction steps [14]:

$$
\begin{aligned}
& \mathrm{TG}+\mathrm{CH}_{3} \mathrm{OH} \underset{k_{2}}{\stackrel{k_{1}}{\rightleftharpoons} \mathrm{DG}}+\mathrm{E} \\
& \mathrm{DG}+\mathrm{CH}_{3} \mathrm{OH} \underset{k_{4}}{\stackrel{k_{3}}{\rightleftharpoons}} \mathrm{MG}+\mathrm{E} \\
& \mathrm{MG}+\mathrm{CH}_{3} \mathrm{OH} \underset{k_{6}}{\stackrel{k_{5}}{\rightleftharpoons}} \mathrm{G}+\mathrm{E}
\end{aligned}
$$

where MG and DG stand for mono and diglyceride, respectively. The specific reactions rates are calculated from the Arrhenius equation,

$k_{j}=k_{0 j} \exp \left(\frac{-E_{\mathrm{a} j}}{R T}\right), \quad j=1, \ldots, 6$,

where $k_{0, j}$ is the pre-exponential factor, $E_{\mathrm{a} j}$ is the energy of activation, $R$ is the ideal gas constant, and $T$ is the temperature of the mixture. The overall reaction rates are

$$
\begin{aligned}
& r_{1}=k_{1} C_{2} C_{1}-k_{2} C_{3} C_{6}, \\
& r_{2}=k_{3} C_{3} C_{1}-k_{4} C_{4} C_{6}, \\
& r_{3}=k_{5} C_{4} C_{1}-k_{6} C_{5} C_{6},
\end{aligned}
$$

where $C_{i}=x_{i} \rho / M_{i}$, is the molar concentration of component $i, i=1$, ..., 6. $x_{i}$ and $M_{i}$ are respectively the component mass fraction and molar mass, and $\rho$ is the density of the liquid mixture. The dynamic model of the reactor is obtained from mass and energy balances. It describes the time evolution of the liquid components mass fractions, $x_{i}$, reactor level, $h$, and temperature, T. Assuming a perfect mixing, and that heat exchanges through the wall reactor with the surrounding air are negligible, it follows that

$$
\begin{aligned}
& m \frac{\mathrm{d} x_{i}}{\mathrm{~d} t}=F\left(x_{0, i}-x_{i}\right)+\phi_{i}, \quad i=1, \ldots, 6, \\
& \rho \mathrm{A} \frac{\mathrm{d} h}{\mathrm{~d} t}=F-V \frac{\mathrm{d} \rho}{\mathrm{d} t}, \quad \text { with } \quad \frac{\mathrm{d} \rho}{\mathrm{d} t}=-\rho^{2} \sum_{i=1}^{6} \frac{1}{\rho_{i}} \frac{\mathrm{d} x_{i}}{\mathrm{~d} t}, \\
& \rho C_{\mathrm{p}} V \frac{\mathrm{d} T}{\mathrm{~d} t}=F C_{\mathrm{pF}}\left(T_{\mathrm{F}}-T\right)+\sum_{j=1}^{3}\left(-\Delta H_{\mathrm{r}}\right)_{j} r_{j} V+Q_{\mathrm{w}},
\end{aligned}
$$


Table 1

Kinetic parameters [41].

\begin{tabular}{llllllll}
$E_{\mathrm{aj}}$ & 16,377 & 19,202 & 17,867 & 19,383 & 4282 & 15,302 & $\mathrm{~J} / \mathrm{mol}$ \\
$k_{j}$ & 0.0730 & 0.0528 & 0.3347 & 0.1655 & 0.3869 & 0.0080 & $\mathrm{~L} /(\mathrm{mol} \mathrm{min})$ \\
\hline
\end{tabular}

Table 2

Feed oil fatty acid mass composition in \% [41].

\begin{tabular}{llllllll}
\hline Lauric & Myristic & Palmitic & Palmitoleic & Stearic & Oleic & Linoleic & Linolenic \\
\hline 0.01 & 0.16 & 10.51 & 0.39 & 2.44 & 44.09 & 36.61 & 5.79 \\
\hline
\end{tabular}

where $m$ is the total mass of liquid in the reactor, $T_{\mathrm{F}}$ and $F$ are the feed temperature and the mass flow rate of methanol, and $Q_{W}$ is the heat duty. The generation reaction terms are given by

$$
\begin{gathered}
\phi_{1}=-\left(r_{1}+r_{2}+r_{3}\right) V M_{1}, \quad \phi_{2}=-r_{1} V M_{2}, \\
\phi_{3}=\left(r_{1}-r_{2}\right) V M_{3}, \quad \phi_{4}=\left(r_{2}-r_{3}\right) V M_{4}, \\
\phi_{5}=r_{3} V M_{5}, \quad \phi_{6}=\left(r_{1}+r_{2}+r_{3}\right) V M_{6} .
\end{gathered}
$$

The density, $\rho$, average molar mass, $M$, and specific heat capacity of the liquid mixture, $C_{\mathrm{p}}$, are calculated assuming the liquid mixture is ideal, such that

$\rho=\left(\sum_{i=1}^{6} \frac{x_{i}}{\rho_{i}}\right)^{-1}, \quad M=\left(\sum_{i=1}^{6} \frac{x_{i}}{M_{i}}\right)^{-1}, \quad C_{\mathrm{p}}=\sum_{i=1}^{6} x_{i} \mathrm{C}_{\mathrm{p} i}$.

The kinetic parameters $E_{\mathrm{a}, j}$ and $k_{j}, j=1, \ldots, 6$, in Table 1 were obtained by [41]. The energies of activation were determined for experimental reaction temperatures ranging from $30^{\circ} \mathrm{C}$ to $60^{\circ} \mathrm{C}$, with a mixing speed of $900 \mathrm{rpm}$, a methanol to oil molar ratio of $6: 1$, and a catalyst mass concentration of $1.0 \%$. The specific reaction rates were obtained for a temperature of $50^{\circ} \mathrm{C}$, with the same methanol to oil molar ratio. The pre-exponential factors in (1) can be computed from these data.

\subsection{Thermo-physical properties}

It should be noted that the simulation of (2) requires the computation of the thermo-physical properties. A recent overview on prediction methods for thermo-physical properties for process modeling and product design of biodiesel manufacturing has been given in [45]. Also, a thermo-physical property calculation framework in support of process modeling, simulation, design, and optimization of biodiesel production processes has been proposed in [46-48]. The transesterification reaction dynamics are simulated using a pseudo-triglyceride (pseudo-TG) approach to characterize the reactor mixture composition. This is done by calculating the average number of $\mathrm{CH}_{2}$ and $\mathrm{CH}=\mathrm{CH}$ groups of the pseudo-triglyceride molecule from the oil fatty acid chains composition. Hence, the transesterification reaction system composition is described in terms of pseudo-monoglycerides, pseudo-diglycerides, pseudo-triglycerides, and of pseudo-fatty acid methyl ester. The rationale behind the pseudo-TG approach is described for instance in [42]. For the oil composition in Table 2, the resulting average number of $\mathrm{CH}_{2}$ and $\mathrm{CH}=\mathrm{CH}$ groups in the pseudofatty acid chain are respectively 13.08 and 1.34 (see Appendix A). The thermo-physical properties for both the feed oil and the reactor mixture are calculated using this pseudo-component approximation. The calculation of the density, specific heat capacity of each component, as well as of the heat of reaction, are explained in Appendix B.

\subsection{Biodiesel product characterization}

The final biodiesel product characteristics have to comply with the standard requirements for the fatty acid methyl esters (FAME) for biodiesel engines. In this work the European standard is used [49]. This standard sets a minimum mass content of FAME (without using any additives) of $96.5 \%$, and several upper concentration limits for various components. The cost function of the NMPC formulation includes the fatty acid methyl ester mass percentage, $\chi_{\mathrm{E}}$, which is calculated in function of the mass of only MG, DG, TG, and E (FAME),

$\chi_{\mathrm{E}}=\frac{m_{\mathrm{E}}}{m_{\mathrm{TG}}+m_{\mathrm{DG}}+m_{\mathrm{MG}}+m_{\mathrm{E}}} \times 100 \%$.

A required minimum value of $\chi_{\mathrm{E}}$ of approximately $98.8 \%$ in the final biodiesel product can be estimated from the data provided in the standard EN 14214:2008 (Appendix C). It is set as the setpoint in the NMPC control problem.

\section{NMPC framework}

The main goal is to control the transesterification process that occurs in the semi-batch reactor by manipulating the methanol feed flow rate and the heat duty. The control objective is to target the desired fatty acid methyl ester mass composition calculated from (3), with a minimum usage of methanol, and of heat duty. The NMPC framework uses the first principle model (2) and the observation model (3). The dynamic and observation models can be represented respectively by

$\dot{x}=f(x, u, d, \theta)$,

$y=g(x)$,

with $f$ and $g$ twice continuously differentiable, where $x \in \mathbb{R}^{n_{\mathrm{s}}}$ is the vector of state variables, $u \in \mathbb{R}^{n_{\mathrm{m}}}$ is the control vector, $d \in \mathbb{R}^{n_{\mathrm{d}}}$ is the disturbance vector, $\theta \in \mathbb{R}^{n_{\theta}}$ is the parameter vector, and $y \in \mathbb{R}^{n_{0}}$ is the vector of output variables. The discrete form of (3) can be represented by $x_{k}=\mathrm{f}\left(x_{k-1}, u_{k-1}, d_{k-1}, \theta, \Delta t\right)$ and $y_{k}=\mathrm{g}\left(x_{k}\right)$, where $\Delta t$ is the sampling period, and $k$ is the time instant index.

The NMPC framework with predictive horizon $p$ and control horizon $m, m \leq p$, involves the solution at every time index $k$, given initial states $x_{k}$, of the following discrete-time constrained dynamic optimization problem:

$\min _{X_{k}, U_{k}} \Psi\left(\tilde{Y}_{k}, U_{k}\right)$

s.t. $\quad \tilde{x}_{k+i}=\mathrm{f}\left(x_{k+i-1}, u_{k+i-1}, d, \theta, \Delta t\right), \tilde{y}_{k+i}=\mathrm{g}\left(\tilde{x}_{k+i}\right), \quad i=1, \ldots, p$

$u_{k+i-1}=u_{k+m-1}, \quad m<i \leq p$

$x_{k+i}-\tilde{x}_{k+i}=0, \quad i=1, \ldots, p-1$

$\tilde{X}_{\mathrm{L}} \leq \tilde{X}_{k} \leq \tilde{X}_{\mathrm{U}}, \quad \tilde{Y}_{\mathrm{L}} \leq \tilde{Y}_{k} \leq \tilde{Y}_{\mathrm{U}}$,

$X_{\mathrm{L}} \leq X_{k} \leq X_{\mathrm{U}}, \quad U_{\mathrm{L}} \leq U_{k} \leq U_{\mathrm{U}}$,

where $\tilde{Y}_{k}$ is the vector of the output predictions, $\tilde{Y}_{k}^{\mathrm{T}}=$ $\left[\tilde{y}_{k+1}^{\mathrm{T}}, \cdots, \tilde{y}_{k+p}^{\mathrm{T}}\right]$, and $\tilde{X}_{k}$ is the vector of the state predictions, $\tilde{X}_{k}^{\mathrm{T}}=$ $\left[\tilde{x}_{k+1}^{\mathrm{T}}, \cdots, \tilde{x}_{k+p}^{\mathrm{T}}\right]$. The dynamic model is solved using a multiple shooting approach. This leads to $p-1$ equality constraints (5d) in order to ensure the continuity of the state variables profiles over the predictive horizon. In (5d) $\tilde{x}_{k+i}$ is the state vector at $k+i$ obtained through the integration of the dynamic model inside 
each sampling time interval, with $t \in\left[t_{k+i-1}, t_{k+i}\right]$, using as initial conditions the nominal states and controls, $x_{k+i-1}$ and $u_{k+i-1}$ respectively. The decision variables of problem (5) are both the state and control trajectories denoted by $X_{k}^{\mathrm{T}}=\left[x_{k+1}^{\mathrm{T}}, \cdots, x_{k+p-1}^{\mathrm{T}}\right]$ and $U_{k}^{\mathrm{T}}=\left[u_{k}^{\mathrm{T}}, \cdots, u_{k+m-1}^{\mathrm{T}}\right]$ respectively. The subscripts ${ }_{\mathrm{L}}$ and $\mathrm{U}_{\mathrm{U}}$ in the nonlinear constraints (5e) and in the decision variables bounds (5f) stand for lower and upper limit value respectively.

The nonlinear programming problem (5) is solved using a successive quadratic programming method with the line search algorithm of [50], and the quadratic programming framework implemented in HQP [51]. The dynamic model is integrated using the solver CVODES, which includes Backward Differentiation Formulas (BDF) method [52]. The automatic differentiation package ADOL-C [53] is used to obtain the Jacobian of the dynamic model. The sensitivities required by the QP-solver to compute the gradient and Hessian of the cost function are obtained by sensitivity integration of CVODES.

\subsection{Control problem setup}

The cost function ( $5 a$ ) is formulated with one output variable, the fatty acid methyl ester mass composition as defined in (3). Two different control configurations are considered in this study: one where the controller manipulates only the methanol feed flow rate $F$, and another where both the methanol feed flow rate $F$ and the heat duty $Q_{w}$ are manipulated variables. Hence, (5a) is defined by of the nominal profiles of the states in (5f). At every time index, the eight state variables are provided by the UKF state estimator to the predictive controller, in order to initialize the model (2). The output vector of the filter includes the concentrations of the mixture pseudo-components (monoglycerides, diglycerides, triglycerides, and fatty acid methyl ester), and of the reactor temperature.

The plant simulator, the predictive controller and the UKF state estimator use the same model formulation and are run in separate programs communicating to each other. The plant simulator provides measurements to the state estimator, which in its turn provides the complete state vector estimate to the NMPC controller. The latter returns the values of the manipulated variables to the plant simulator. This simulator does integrate the model over a time period that does include the computational delay time. The computational framework is implemented in $\mathrm{C}++$, and runs on a GNU Linux operating system.

\section{Simulation results}

The simulation study is performed with a mass of $1000 \mathrm{~kg}$ of used vegetable oil with the composition given in Table 2. It is assumed that the reactor diameter is $1 \mathrm{~m}$, and the initial oil and methanol are at the ambient temperature of $20^{\circ} \mathrm{C}$. Several assumptions are considered here to simplify the description of this reacting system. As mentioned before, it is assumed that the mixing is perfect, and that there are no heat losses to the reactor

$\Psi\left(\tilde{Y}_{k}, U_{k}\right)=q_{1} \sum_{i=1}^{p}\left(\chi_{\mathrm{E}, \mathrm{sp}, k+i}-\tilde{\chi}_{\mathrm{E}, k+i}\right)^{2}+q_{2} \sum_{i=1}^{m}\left(Q_{\mathrm{w}, k+i-1}-Q_{\mathrm{w}, \mathrm{ref}, k+i-1}\right)^{2}+q_{3} \sum_{i=1}^{m}\left(F_{k+i-1}-F_{\mathrm{ref}, k+i-1}\right)^{2}$,

where $q_{1}, q_{2}$, and $q_{3}$ are weighting scalars, respectively with units of $\%^{-2}, \mathrm{~kW}^{-2}$, and $(\mathrm{s} / \mathrm{kg})^{2}$. The reference values of the manipulated variables over the control horizon are set to zero in order to penalize the consumption of methanol and heat duty usage. Physical limits on the reactor mixture components mass fraction, level, temperature, methanol feed rate, and heat duty are incorporated in the problem such that: $0 \leq x_{i} \leq 1 ; 0 \mathrm{~m} \leq h \leq 3 \mathrm{~m} ; 15^{\circ} \mathrm{C} \leq T<65^{\circ} \mathrm{C}$; $0 \mathrm{~kg} / \mathrm{s} \leq F \leq 5 \mathrm{~kg} / \mathrm{s} ;-20 \mathrm{~kW} \leq Q_{\mathrm{W}} \leq 36 \mathrm{~kW}$. The lower limit of $Q_{\mathrm{w}}$ is negative such that the reactor mixture can be either heated $\left(Q_{W}>0\right)$ with electrical heating equipment, or cooled $\left(Q_{w}<0\right)$ with fresh water, as needed. The upper and lower limit values are the same for both the predictions of the state variables in (5e) and the bounds surroundings. The pseudo-triglyceride approach is adopted to characterize the reactor mixture contents and the reaction system. The thermo-physical properties of each component in the mixture are considered to be constant and equal to their values at a temperature of $50^{\circ} \mathrm{C}$ (Appendix B).

\subsection{Open loop response}

First of all, the open loop simulation of the reactor is considered in batch mode, with an initial oil mixture and operating conditions similar to those of [41], except for the presence of water and of free
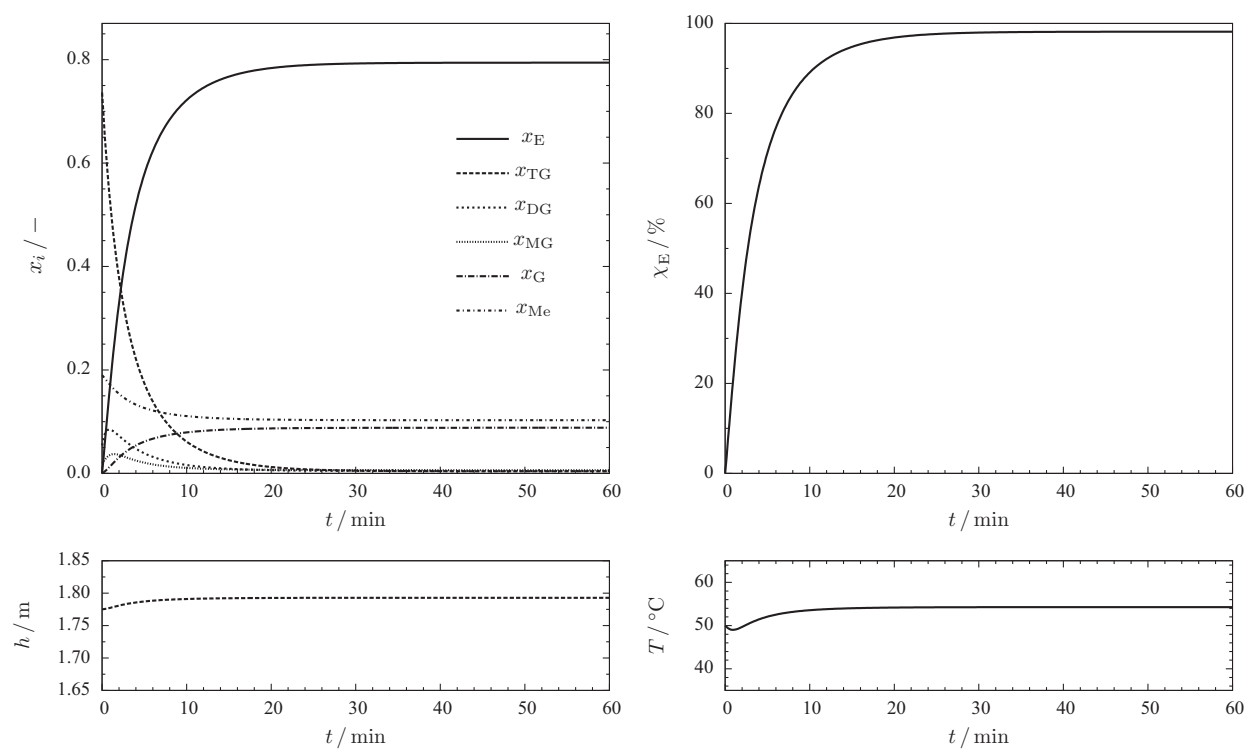

Fig. 1. Mass fractions of the components, $x_{i}$, FAME mass percentage $\chi_{\mathrm{E}}$ as calculated from ( 3 ), level and temperature open loop responses. 

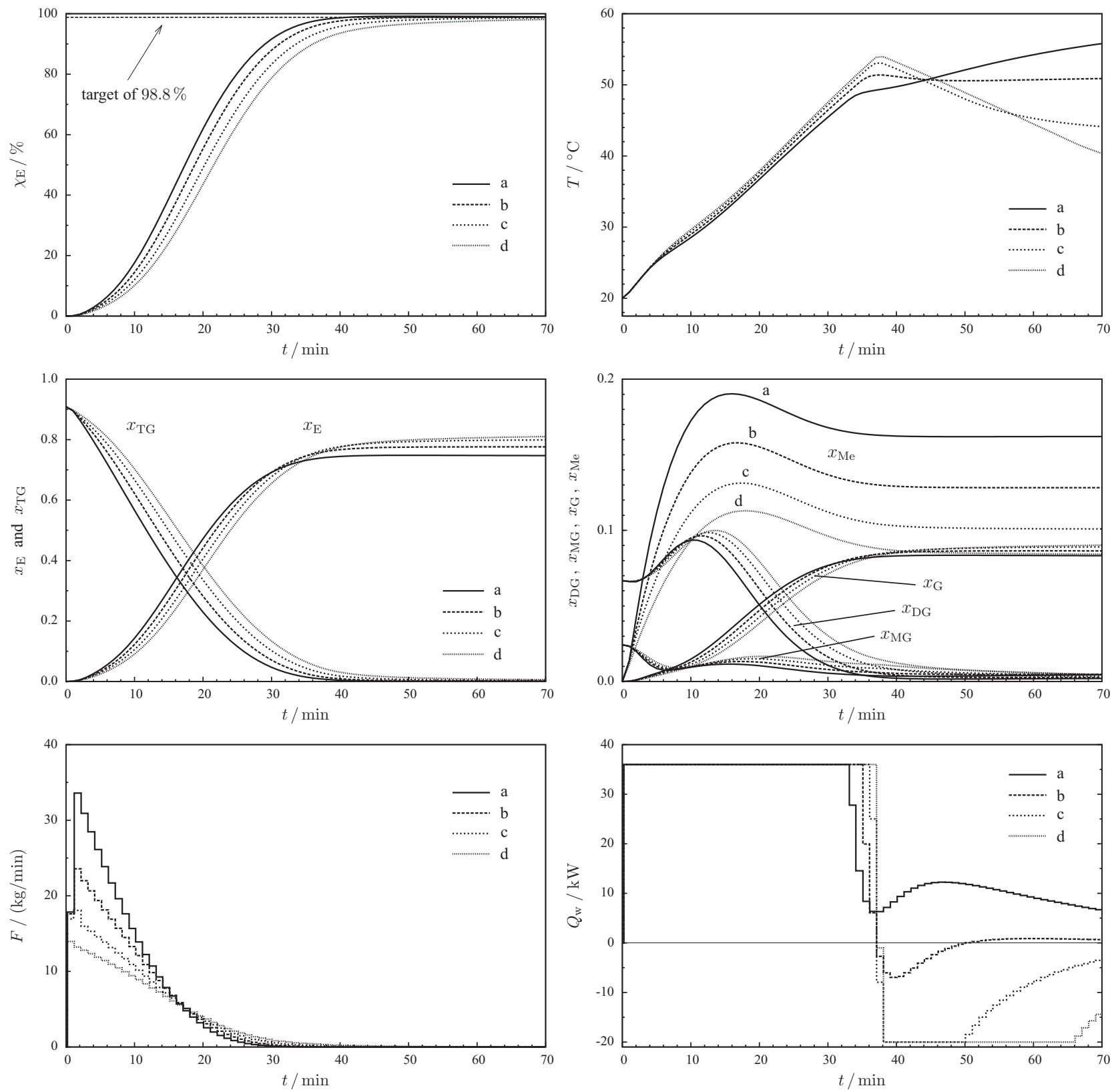

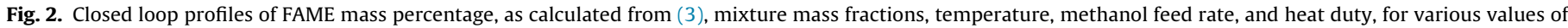
$q_{3}$ : (a) $2000(\mathrm{~s} / \mathrm{kg})^{2}$; (b) $3500(\mathrm{~s} / \mathrm{kg})^{2}$; (c) $6000(\mathrm{~s} / \mathrm{kg})^{2}$; and (d) $9000(\mathrm{~s} / \mathrm{kg})^{2}$.

fatty acid which is not considered in the initial oil mixture here. Thus, using the data of [41] the initial oil mixture mass composition is as follows: $90.90 \%$ of TG, $6.67 \%$ of DG, and $2.43 \%$ of MG. The reactor operates at atmospheric pressure, and the total mass of methanol added to the oil corresponds to a molar methanol/oil ratio of $R_{\mathrm{AO}}=6$. For 1 ton of used vegetable oil characterized by a pseudo-TG with a molar mass of $873.06 \mathrm{~g} / \mathrm{mol}$ (Table B1), a mass of $234.34 \mathrm{~kg}$ of methanol is obtained for the above molar methanol/oil ratio, with the number of moles of oil given by the sum of the moles of initial pseudo-TG, pseudo-DG, and pseudo-MG. It is assumed that both methanol and oil are pre-heated from $20^{\circ} \mathrm{C}$ up to $50^{\circ} \mathrm{C}$. Fig. 1 shows the evolution of the transesterification reaction over $60 \mathrm{~min}$. The final reactor mass composition is: $10.28 \%$ of methanol; $0.40 \%$ of TG; $0.46 \%$ of DG; $0.62 \%$ of MG; $8.82 \%$ of glycerol; and $79.41 \%$ of fatty acid methyl ester.

Considering a complete separation of methanol and glycerol, the FAME mass percentage calculated from (3), $\chi_{\mathrm{E}}$, is of $97.2 \%$. In a similar manner, one obtains the values of $\chi_{\mathrm{TG}}=0.50 \%, \chi_{\mathrm{DG}}=0.56 \%$, and $\chi_{\mathrm{MG}}=0.77 \%$. It can be concluded that for these scenarios only the value for MG does comply with the standard Appendix C. Slight variations in the mixture level and temperature are observed at the beginning of the reaction because of the effect of composition changes on the mixture density and on the overall heat of reaction. These open loop results were obtained with a GNU Octave program using the solver CVODES [52].

It takes approximately $29 \mathrm{~min}$ to pre-heat one ton of used vegetable oil with the reactor electrical heating equipment delivering its maximum power of $36 \mathrm{~kW}$. To pre-heat the mass of methanol it would require approximately $9 \mathrm{~min}$. Considering an industry cost of electricity of $€ 0.13$ per $\mathrm{kWh}$, the cost to heat the oil is of $€ 2.48$, whereas it costs $€ 0.76$ to heat the methanol. For the above molar methanol/oil ratio the methanol costs $€ 60$. This value is obtained for an estimated cost of $€ 10$ per molar methanol/oil ratio unit and one ton of oil. The total cost for this open loop 

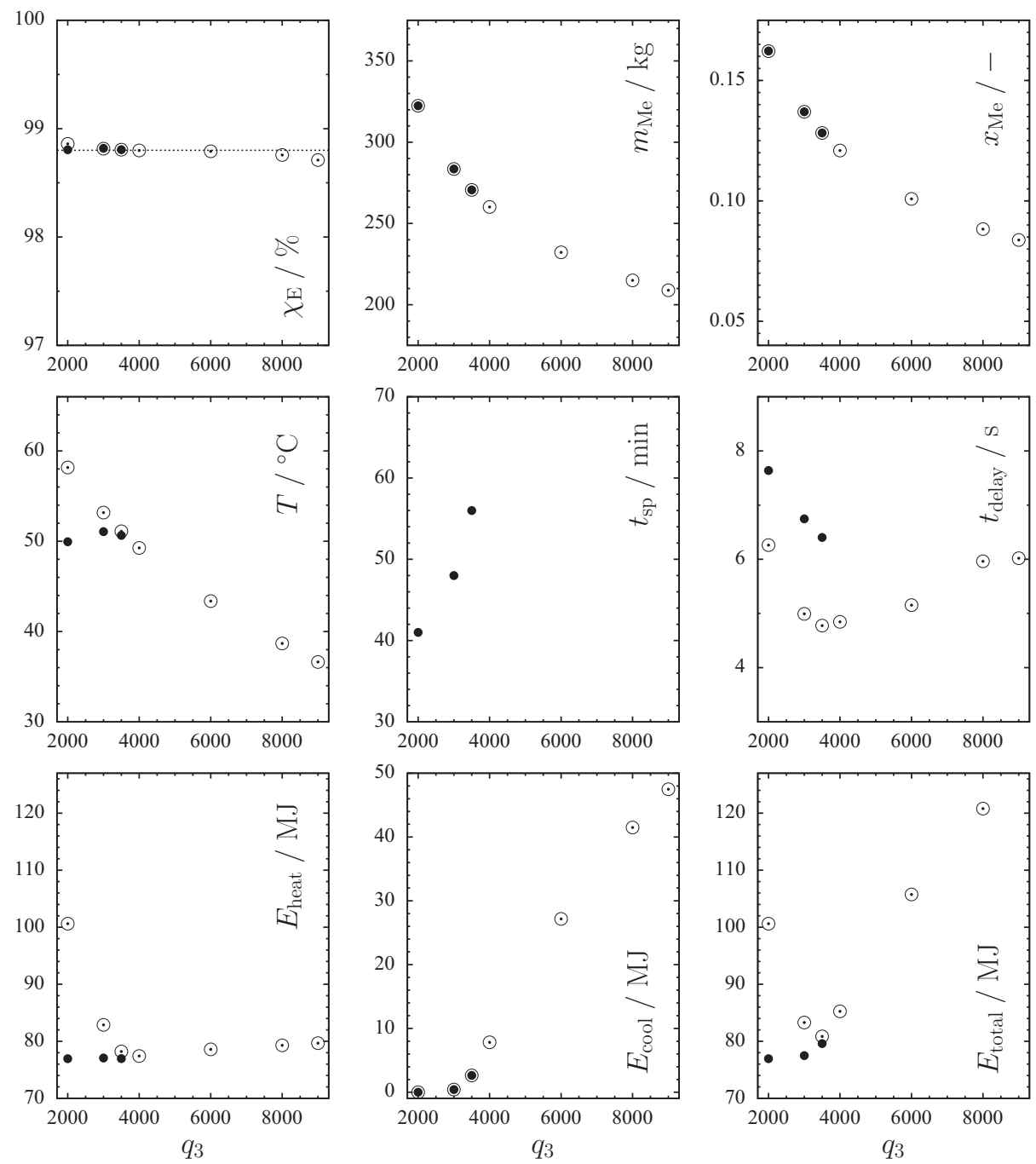

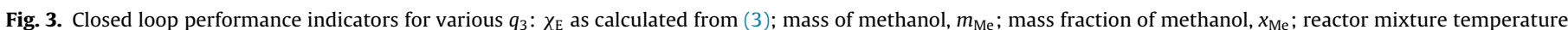

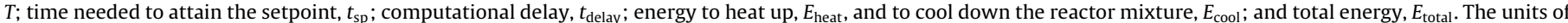
$q_{3}$ are $(\mathrm{s} / \mathrm{kg})^{2}$.

scenario accounting for the methanol and the heating of the mixture is of $€ 63.24$.

\subsection{Closed loop response}

The predictive and control horizons are chosen such that $p=60$ and $m=20$, respectively. The sampling time period is $\Delta t=1 \mathrm{~min}$. These were defined through several simulations trials. The length of the predictive horizon of $1 \mathrm{~h}$ is defined from the observation of the dynamic profiles in open loop (Fig. 1). Several runs were made in order to assess the length of the control horizon, and the weighting scalars in (6) are tuned by trial and error through the analysis of various closed loop simulations. Their tuning is made to balance the controller effort in manipulating the methanol feed flow rate and the heat duty. The weighting parameter $q_{1}$ is fixed to $1 \%-2$, and $q_{2}=10^{-10} \mathrm{~kW}^{-2}$. The difference in orders of magnitude is determined by the scaling of the corresponding terms in the cost function. Fig. 2 shows closed loop profiles of $\chi_{\mathrm{E}}$, of the mixture mass fraction composition and temperature, and of the manipulated variables over $70 \mathrm{~min}$ of operation for four values of $q_{3}$ : (a) $2000(\mathrm{~s} / \mathrm{kg})^{2}$; (b) $3500(\mathrm{~s} / \mathrm{kg})^{2}$; (c) $6000(\mathrm{~s} / \mathrm{kg})^{2}$; (d) $9000(\mathrm{~s} / \mathrm{kg})^{2}$.

One emphasizes that the used vegetable oil and the methanol are not pre-heated as in the open loop case (Section 4.1). The controller manipulates the heating power to heat the reactor mixture. Moreover, the addition of methanol at $20^{\circ} \mathrm{C}$ along the reaction process has a cooling effect on the reactor mixture. One observes that the heat duty effort decreases with the increase of the penalty parameter $q_{3}$. To compensate for this, the controller increases the total mass of methanol added to the reactor in order to comply with the desired value of $\chi_{\mathrm{E}, \mathrm{sp}}=98.8 \%$. Nevertheless, this objective is not fulfilled with higher values of $q_{3}$ such as in cases c) and d). Also, remark that profiles show operating conditions during certain periods of time where the manipulated variable $Q_{w}$ is either at its upper or lower limit. Fig. 3 provides additional performance control indicators for seven different values of $q_{3}$, varying from 2000 to $9000(\mathrm{~s} / \mathrm{kg})^{2}$. The open circles are values obtained after $100 \mathrm{~min}$ of operation, and the filled circles represent values obtained for the time when the setpoint of $\chi_{\mathrm{E}}$ is attained. The setpoint of $98.8 \%$ is reached within the time period of $100 \mathrm{~min}$ only for $q_{3}$ equal to 2000,3000 , and $3500(\mathrm{~s} / \mathrm{kg})^{2}$, respectively at time ( $t_{\mathrm{sp}}$ in Fig. 3) 41, 48, and $56 \mathrm{~min}$. However, one can observe that for $q_{3}$ equal to $4000,6000,8000$, and $9000(\mathrm{~s} / \mathrm{kg})^{2}, \chi_{\mathrm{E}}$ is still very close (less than $0.1 \%$ ) to the setpoint. The relaxation of $q_{3}$ favors an aggressive control action that results in an increase of methanol consumption (see the mass of methanol added, $m_{\mathrm{Me}}$, and its mass fraction, $x_{\mathrm{Me}}$ ) and an increase of energy spent to heat 
Table 3

Parameter $q_{3}$, mass $\left(m_{\mathrm{Me}}\right)$ and $\operatorname{cost}\left(C_{\mathrm{Me}}\right)$ of methanol, volume of fresh water $\left(V_{\text {water }}\right)$, and energy $\left(C_{\text {heat }}\right.$ and $\left.C_{\text {cool }}\right)$, and total $\left(C_{\text {total }}\right)$ costs.

\begin{tabular}{|c|c|c|c|c|c|c|}
\hline$q_{3}(\mathrm{~s} / \mathrm{kg})^{2}$ & $m_{\mathrm{Me}}(\mathrm{kg})$ & $C_{\mathrm{Me}}(€)$ & $C_{\text {heat }}(€)$ & $V_{\text {water }}\left(\mathrm{m}^{3}\right)$ & $C_{\text {cool }}(€)$ & $C_{\text {total }}(€)$ \\
\hline 2000 & 322.38 & 87.84 & 3.63 & 0.00 & 0.00 & 91.47 \\
\hline 3000 & 283.54 & 77.26 & 2.99 & 0.01 & 0.02 & 80.27 \\
\hline 3500 & 270.67 & 73.75 & 2.82 & 0.06 & 0.11 & 76.68 \\
\hline 4000 & 260.13 & 70.88 & 2.80 & 0.19 & 0.32 & 73.99 \\
\hline 6000 & 232.21 & 63.27 & 2.84 & 0.65 & 1.11 & 67.22 \\
\hline 8000 & 214.99 & 58.58 & 2.86 & 0.99 & 1.69 & 63.13 \\
\hline 9000 & 208.94 & 56.93 & 2.88 & 1.14 & 1.93 & 61.74 \\
\hline
\end{tabular}

the mixture ( $\left.E_{\text {heat }}\right)$. On the other hand, higher values of $q_{3}$ increase energy usage to heat up the reactor mixture as well as, later on during the operation, to cool down the reactor mixture with fresh water $\left(E_{\text {cool }}\right)$. It is noticeable that a higher rate of methanol consumption reduces the time needed to attain the setpoint, $\left(t_{\mathrm{sp}}\right.$ in Fig. 3). The average computational delay, $t_{\text {delay }}$, varies between 4 and 8 seconds on a $3.2 \mathrm{GHz}$ processor, running GNU Linux.

Table 3 summarizes the operation costs associated to methanol and energy usage over a time of operation of $100 \mathrm{~min}$. The energy cost to cool the reactor mixture is calculated from the amount of fresh water that would be needed assuming a sensible heat of $10^{\circ} \mathrm{C}$ and that the cost of fresh water is of $€ 1.70 / \mathrm{m}^{3}$.

Table 3 shows the effect of the tuning parameter $q_{3}$ on methanol and heat duty costs. As it can be observed in Fig. 3, an increase of $q_{3}$ decreases the amount of methanol added to the reactor. On the other hand, it increases the usage of fresh water, with more than one cubic meter for $q_{3}=9000(\mathrm{~s} / \mathrm{kg})^{2}$ (Table 3). As for heating the mixture, the cost of energy usage decreases up to a certain point and then it increases slowly with $q_{3}$. Overall, the total cost of these three components decreases with $q_{3}$ (Table 3 ), but above a certain value of $q_{3}$ it is not possible to attain the desired value of $\chi_{\mathrm{E}}$ (Fig. 3). Considering the presented analysis, the methanol constitutes here the major contribution for the cost of the transesterification process. Obviously, additional costs need to be taken into account to provide a thoroughly analysis of the process performance, but are beyond the scope of this work. These would include for instance the costs of the separation of the residual methanol, and of the glycerol.

\section{Conclusions}

Nonlinear model predictive control (NMPC) is applied by simulation to the control of a transesterification semi-batch reactor. The controller uses a first principle model to predict the dynamics of the reactor. The performance of the closed loop system is demonstrated with a control configuration where both the methanol feed rate and heat duty are manipulated. In particular the effect of tuning the control parameters is shown to be of paramount importance to balance the multi-variable control effort and the consequent operating costs.

This work may be further developed with an experimental study on the effect of plant/model mismatch present in real production facilities. This would enable a thorough study of the performance of the state estimator and of the issue of model observability and their impact on the overall closed loop performance of the system.

\section{Acknowledgements}

This work was developed under project APCFAME, reference $3509 / 2009$, in consortium between Ciengis, SA and the Faculty of Sciences and Technology of the University of Coimbra, with financial support of QREN via Mais Centro regional program and European Union via FEDER framework program. Part of the work made use of the free software package GNU Octave, and the authors are grateful for the support of the Octave development community.

\section{Appendix A. Pseudo-triglyceride approach}

The average number of $\mathrm{CH}_{2}$ groups, $n$, and $\mathrm{CH}=\mathrm{CH}$ groups, $m$, of the pseudo-fatty acid chain are calculated as follows:

$n=\sum_{j}^{N} n_{j} x_{j}, \quad m=\sum_{j}^{N} m_{j} x_{j}$,

where $N$ is the number of fatty acid chains in the oil composition, $n_{j}$ and $m_{j}$ are respectively the number of $\mathrm{CH}_{2}$ and $\mathrm{CH}=\mathrm{CH}$ groups in the $j$ th fatty acid chain, and $x_{j}$ is its molar fraction in the feed oil composition. For the feed oil composition in Table $2, N=8$, and it follows that $n=13.08$ and $m=1.34$ (see Table A1). This means that the feed oil composition could be represented approximately by a pseudo-fatty acid chain with one double bond and $13 \mathrm{CH}_{2}$ groups. Nevertheless, since this is an approximative representation, the calculated values of $n$ and $m$ are used to compute the properties of the corresponding pseudo-monoglyceride, pseudo-diglyceride, pseudo-triglyceride, and pseudo-fatty acid methyl ester molecules (see Appendix B). The molar mass of these pseudo-components is given in Table B1.

\section{Appendix B. Feed oil and reactor mixture thermo-physical properties}

The thermo-physical properties of the feed oil and reactor mixture are evaluated in function of the composition and of the temperature, assuming that the mixture is ideal. The reactor mixture content representation is approximated with the pseudocomponents listed in Appendix A. The density of the pseudo-fatty acid methyl ester (FAME), pseudo-monoglyceride (MG), pseudodiglyceride (DG), pseudo-triglyceride (TG), and glycerol (G) are calculated with the group contribution method GCVOL [54]. The density of methanol is calculated using a Rackett based equation, as described by [55]. Table B1 gives the density for temperatures of $40^{\circ} \mathrm{C}, 50^{\circ} \mathrm{C}$, and $60^{\circ} \mathrm{C}$. The density of the pseudo-MG and pseudoDG are the average density of the pseudo 1-monoglyceride and pseudo 2-monoglyceride, and of the pseudo 1,2-diglyceride and pseudo 1,3-diglyceride, respectively.

Table A1

Feed oil fatty acid mass and molar fraction composition.

\begin{tabular}{lllllrr}
\hline Fatty acid & & $\begin{array}{l}\text { No. of } \\
\mathrm{CH}=\mathrm{CH} \\
\text { groups }\end{array}$ & $\begin{array}{l}\text { No. of } \\
\mathrm{CH}_{2} \\
\text { groups }\end{array}$ & $\begin{array}{l}\text { Molar } \\
\text { mass } \\
(\mathrm{g} / \mathrm{mol})\end{array}$ & $\begin{array}{l}\%(m / m) \\
(\text { Table } 2)\end{array}$ & $\%(\mathrm{~mol} / \mathrm{mol})$ \\
\hline C12:0 & Lauric & 0 & 10 & 200.32 & 0.01 & 0.014 \\
C14:0 & Myristic & 0 & 12 & 228.37 & 0.16 & 0.195 \\
C16:0 & Palmitic & 0 & 14 & 256.42 & 10.51 & 11.408 \\
C16:1 & Palmitoleic & 1 & 12 & 254.41 & 0.39 & 0.427 \\
C18:0 & Stearic & 0 & 16 & 284.48 & 2.44 & 2.387 \\
C18:1 & Oleic & 1 & 14 & 282.46 & 44.09 & 43.446 \\
C18:2 & Linoleic & 2 & 12 & 280.45 & 36.61 & 36.335 \\
C18:3 & Linolenic & 3 & 10 & 278.43 & 5.79 & 5.788 \\
& & $m=1.34$ & $n=13.08$ & & & \\
\hline
\end{tabular}


Table B1

Molar mass, density, and specific heat capacity of pseudo-components*, glycerol, and methanol.

\begin{tabular}{|c|c|c|c|c|c|c|c|}
\hline & \multirow[t]{2}{*}{ Molar mass (mol/g) } & \multicolumn{3}{|c|}{ Density (g/L) } & \multicolumn{3}{|c|}{ Heat capacity $(\mathrm{J} /(\mathrm{g} \mathrm{K}))$} \\
\hline & & $40^{\circ} \mathrm{C}$ & $50^{\circ} \mathrm{C}$ & $60^{\circ} \mathrm{C}$ & $40^{\circ} \mathrm{C}$ & $50^{\circ} \mathrm{C}$ & $60^{\circ} \mathrm{C}$ \\
\hline $\mathrm{TG}^{*}$ & 873.06 & 922.15 & 914.37 & 906.88 & 2.008 & 2.052 & 2.097 \\
\hline $\mathrm{DG}^{*}$ & 612.74 & 949.61 & 941.90 & 934.45 & 2.065 & 2.119 & 2.174 \\
\hline MG* & 352.42 & 998.71 & 990.56 & 982.57 & 2.204 & 2.284 & 2.364 \\
\hline $\mathrm{E}^{*}$ & 292.36 & 863.62 & 856.37 & 849.25 & 2.034 & 2.084 & 2.134 \\
\hline G & 92.09 & 1352.18 & 1346.60 & 1339.96 & 2.462 & 2.509 & 2.556 \\
\hline Methanol & 32.04 & 780.85 & 769.00 & 756.91 & 2.632 & 2.705 & 2.785 \\
\hline
\end{tabular}

Table B2

Heat of reaction in $\mathrm{kJ} / \mathrm{mol}$.

\begin{tabular}{lllll}
\hline$T\left({ }^{\circ} \mathrm{C}\right)$ & $\Delta H_{\mathrm{r}, 1}$ & $\Delta H_{r, 2}$ & $\Delta H_{r, 3}$ & $\Delta H_{r}$ \\
\hline 40 & 15.046 & 36.246 & -57.761 & -6.468 \\
50 & 15.338 & 36.538 & -58.275 & -6.399 \\
60 & 15.699 & 36.899 & -58.906 & -6.309 \\
\hline
\end{tabular}

Table C1

Standard mass content requirements, and mass compositions I and II, in \%.

\begin{tabular}{lclrr}
\hline Component & Min & Max & I & II \\
\hline E (FAME) & 96.5 & - & 98.53 & 98.80 \\
TG & - & 0.20 & 0.20 & 0.20 \\
DG & - & 0.20 & 0.20 & 0.20 \\
MG & - & 0.80 & 0.80 & 0.80 \\
Methanol & - & 0.20 & 0.20 & \\
Sulfated ash & - & 0.02 & 0.02 & \\
Water & - & 0.05 & 0.05 & \\
& & & 100.00 & 100.00 \\
\hline
\end{tabular}

As for the specific heat capacity of the individual components, [45] recommends the methods of both $[46,48,56]$ for predicting specific heat capacities of triglycerides and feed oils. However, [45] emphasizes that it is not recommendable to use the methods of [46] for the pseudo-TG approach. In this work the specific heat capacity of the pseudo components is calculated using the group contribution method of [56]. The specific heat capacity of methanol is calculated according to [57]. Finally, the specific heat capacity of glycerol is computed using the method of [58]. Specific heat capacity values for temperatures of $40^{\circ} \mathrm{C}, 50^{\circ} \mathrm{C}$, and $60^{\circ} \mathrm{C}$, are given in Table B1.

An estimation of the heat of reaction of the overall reactions in Section 2 in function of the mixture temperature is calculated from:

$$
\Delta H_{\mathrm{r}, q}=\Delta H_{\mathrm{r}, q}^{0}+\int_{T_{0}}^{T}\left(\sum_{p}^{N_{\mathrm{p}}} C_{p, p}-\sum_{r}^{N_{\mathrm{r}}} C_{p, r}\right) \mathrm{d} T, \quad q=1, \ldots, 3,
$$

where $N_{\mathrm{p}}$ is the number of products, $N_{\mathrm{r}}$ is the number of reactants, and $\Delta H_{\mathrm{r}, q}^{0}$ is the heat of reaction $q$ at temperature $T_{0}=298.15 \mathrm{~K}$. $\Delta H_{\mathrm{r}, q}^{0}$ is obtained using the standard state enthalpy of formation at $298.15 \mathrm{~K}$, and it is calculated with the group contribution method of [59]. Table B2 gives the heat of reaction of the overall reactions 1 , 2 , and 3, and the heat the overall transesterification reaction, $\Delta H_{\mathrm{r}}$, for temperatures of $40^{\circ} \mathrm{C}, 50^{\circ} \mathrm{C}$, and $60^{\circ} \mathrm{C}$.

\section{Appendix C. Biodiesel quality indicators}

Table C1 contains an excerpt of the European standard requirements for the fatty acid methyl esters (FAME or E) for biodiesel engines [49]. The biodiesel mass fraction composition I is set assuming that all the components (except E) are present in the biodiesel with the maximum mass percentage permitted by the standard. The biodiesel mass fraction composition II is calculated from composition I with the mass of only E, TG, DG, and MG. The resulting mass percentage of $\mathrm{E}$ in the biodiesel of approximately $98.8 \%$ is used in the NMPC formulation as a control target for $\chi_{E}$.

\section{References}

[1] B. Salvi, N. Panwar, Biodiesel resources and production technologies - a review, Renew. Sust. Energy Rev. 16 (6) (2012) 3680-3689.

[2] G. Santori, G.D. Nicola, M. Moglie, F. Polonara, A review analyzing the industrial biodiesel production practice starting from vegetable oil refining, Appl. Energy 92 (2012) 109-132.

[3] C. Enweremadu, M. Mbarawa, Technical aspects of production and analysis of biodiesel from used cooking oil - a review, Renew. Sust. Energy Rev. 13 (9) (2009) 2205-2224.

[4] D.Y. Leung, X. Wu, M. Leung, A review on biodiesel production using catalyzed transesterification, Appl. Energy 87 (4) (2010) 1083-1095.

[5] S.G. Zavarukhin, V.A. Yakovlev, V.N. Parmon, V.G. Sister, E.M. Ivannikova, O.A. Eliseeva, Development of a process for refining rape seed oil into biodiesel and high-cetane components of diesel fuel, Chem. Technol. Fuels Oils 46 (1) (2010) $1-8$

[6] S. Lee, D. Posarac, N. Ellis, Process simulation and economic analysis of biodiesel production processes using fresh and waste vegetable oil and supercritical methanol, Chem. Eng. Res. Des. 89 (12) (2011) 2626-2642.

[7] A.H. West, D. Posarac, N. Ellis, Assessment of four biodiesel production processes using HYSYS Plant, Bioresour. Technol. 99 (14) (2008) 6587-6601.

[8] P.P. Oh, H.L.N. Lau, J. Chen, M.F. Chong, Y.M. Choo, A review on conventional technologies and emerging process intensification (PI) methods for biodiesel production, Renew. Sust. Energy Rev. 16 (7) (2012) 5131-5145.

[9] F.S. Mjalli, M.A. Hussain, Approximate predictive versus self-tuning adaptive control strategies of biodiesel reactors, Ind. Eng. Chem. Res. 48 (24) (2009) 11034-11047

[10] D. Darnoko, M. Cheryan, Kinetics of palm oil transesterification in a batch reactor, J. Am. Oil Chem. Soc. 77 (2000) 1263-1267.

[11] F.S. Mjalli, L. Kim San, K. Chai Yin, M.A. Hussain, Dynamics and control of a biodiesel transesterification reactor, Chem. Eng. Technol. 32 (1) (2009) 13-26.

[12] H.Y. Kuen, F.S. Mjalli, Y.H. Koon, Recursive least squares-based adaptive contro of a biodiesel transesterification reactor, Ind. Eng. Chem. Res. 49 (22) (2010) $11434-11442$

[13] Y.H. Shen, J.K. Cheng, J.D. Ward, C.C. Yu, Design and control of biodiesel production processes with phase split and recycle in the reactor system, J. Taiwan Inst. Chem. Eng. 42 (5) (2011) 741-750.

[14] H. Noureddini, D. Zhu, Kinetics of transesterification of soybean oil, J. Am. Oil Chem. Soc. 74 (11) (1997) 1457-1463.

[15] P.T. Benavides, U. Diwekar, Optimal control of biodiesel production in a batch reactor: part I: Deterministic control, Fuel 94 (2012) 211-217.

[16] P.T. Benavides, U. Diwekar, Optimal control of biodiesel production in a batch reactor: part II: Stochastic control, Fuel 94 (2012) 218-226.

[17] P.T. Benavides, U. Diwekar, Studying various optimal control problems in biodiesel production in a batch reactor under uncertainty, Fuel 103 (2012) 585-592.

[18] W. Wali, A. Al-Shamma'a, K.H. Hassan, J. Cullen, Online genetic-ANFIS temperature control for advanced microwave biodiesel reactor, J. Process Control 22 (7) (2012) 1256-1272.

[19] C.S. Bildea, A.A. Kiss, Dynamics and control of a biodiesel process by reactive absorption, Chem. Eng. Res. Des. 89 (2) (2011) 187-196.

[20] S.J. Qin, T.A. Badgwell, A survey of industrial model predictive control technology, Control Eng. Pract. 11 (7) (2003) 733-764

[21] E.F. Camacho, C. Bordons, Model Predictive Control, Advanced Textbooks in Control and Signal Processing, Springer-Verlag, London, 2004.

[22] L. Magni, D.M. Raimondo, F. Allgöwer (Eds.), Nonlinear Model Predictive Control - Towards New Challenging Applications, Vol. 384 of Lecture Notes in Control and Information Sciences, Springer, 2009.

[23] J.H. Lee, Model predictive control: Review of the three decades of development Int. J. Control Automat. Syst. 9 (3) (2011) 415-424.

[24] L.O. Santos, N.M.C. Oliveira, L.T. Biegler, Reliable and Efficient Optimization Strategies for Nonlinear Model Predictive Control, in: J.B. Rawlings (Ed.), Proc. of DYCORD+'95, Helsingør, Denmark, Elsevier Science, Oxford, 1995, pp. 33-38.

[25] L.O. Santos, P.A.F.N.A. Afonso, J.A.A.M. Castro, N.M.C. Oliveira, L.T. Biegler, Online implementation of nonlinear MPC: an experimental case study, Control Eng. Pract. 9 (2001) 847-857. 
[26] H.G. Bock, K.J. Plitt, A multiple shooting algorithm for direct solution of optimal control, in: Proc. 9th IFAC World Congress, Pergamon Press, Budapest, 1984, pp. $242-247$.

[27] Z.K. Nagy, B. Mahn, R. Franke, F. Allgöwer, Evaluation study of an efficient output feedback nonlinear model predictive control for temperature tracking in an industrial batch reactor, Control Eng. Pract. 15 (7) (2007) 839-850.

[28] S.J.Julier, J.K. Uhlmann, Unscented filtering and nonlinear estimation, Proc. IEEE 92 (3) (2004) 401-422.

[29] M. Diehl, H. Bock, J.P. Schlöder, R. Findeisen, Z. Nagy, F. Allgöwer, Real-time optimization and nonlinear model predictive control of processes governed by differential-algebraic equations, J. Process Control 12 (4) (2002) 577-585.

[30] V.M. Zavala, L.T. Biegler, Optimization-based strategies for the operation of low-density polyethylene tubular reactors: nonlinear model predictive control, Comput. Chem. Eng. 33 (2009) 1735-1746.

[31] C. Kirches, L. Wirsching, H. Bock, J. Schlöder, Efficient direct multiple shooting for nonlinear model predictive control on long horizons, J. Process Control 22 (3) (2012) 540-550

[32] R. Lopez-Negrete, F.J. D’Amato, L.T. Biegler, A. Kumar, Fast nonlinear model predictive control: Formulation and industrial process applications, Comput. Chem. Eng. 51 (2013) 55-64.

[33] B.A. Foss, T.A. Johansen, A.V. Sørensen, Nonlinear predictive control using local models - applied to a batch fermentation process, Control Eng. Pract. 3 (3) (1995) 389-396.

[34] H. Musch, G. Barton, T. Langrish, A. Brooke, Nonlinear model predictive control of timber drying, Comput. Chem. Eng. 22 (3) (1998) 415-425.

[35] H. Seki, M. Ogawa, S. Ooyama, K. Akamatsu, M. Ohshima, W. Yang, Industrial application of a nonlinear model predictive control to polymerization reactors, Control Eng. Pract. 9 (8) (2001) 819-828.

[36] J. Valappil, C. Georgakis, Nonlinear model predictive control of end-use properties in batch reactors, AIChE J. 48 (9) (2002) 2006-2021.

[37] D.C. Silva, N.M. Oliveira, Optimization and nonlinear model predictive control of batch polymerization systems, Comput. Chem. Eng. 26(4-5)(2002)649-658.

[38] O. Abel, W. Marquardt, Scenario-integrated on-line optimisation of batch reactors, J. Process Control 13 (8) (2003) 703-715.

[39] L.S. Balasubramhanya, F.J. Doyle III, Nonlinear model-based control of a batch reactive distillation column, J. Process Control 10 (2-3) (2000) 209-218.

[40] F. Xaumier, M.-V.L. Lann, M. Cabassud, G. Casamatta, Experimental application of nonlinear model predictive control: temperature control of an industrial semi-batch pilot-plant reactor, J. Process Control 12 (6) (2002) 687-693.

[41] H.J. Berchmans, K. Morishita, T. Takarada, Kinetic study of methanolysis of Jatropha curcas-waste food oil mixture, J. Chem. Eng.Jpn. 43 (8) (2010)661-670.

[42] A.-F. Chang, Y.A. Liu, Integrated process modeling and product design of biodiesel manufacturing, Ind. Eng. Chem. Res. 49 (3) (2010) 1197-1213.

[43] S. Espinosa, T. Fornari, S.B. Bottini, E.A. Brignole, Phase equilibria in mixtures of fatty oils and derivatives with near critical fluids using the GC-EOS model, J. Supercrit. Fluids 23 (2) (2002) 91-102.
[44] P.M. Ndiaye, E. Franceschi, D. Oliveira, C. Dariva, F.W. Tavares, J.V. Oliveira, Phase behavior of soybean oil, castor oil and their fatty acid ethyl esters in carbon dioxide at high pressures, J. Supercrit. Fluids 37 (1) (2006) 29-37.

[45] Y.-C. Su, Y.A. Liu, C.A.D. Tovar, R. Gani, Selection of prediction methods fo thermophysical properties for process modeling and product design of biodiesel manufacturing, Ind. Eng. Chem. Res. 50 (11) (2011) 6809-6836.

[46] L. Zong, S. Ramanathan, C.-C. Chen, Fragment-based approach for estimating thermophysical properties of fats and vegetable oils for modeling biodiesel production processes, Ind. Eng. Chem. Res. 49 (2) (2010) 876-886.

[47] L. Zong, S. Ramanathan, C.-C. Chen, Correction to fragment-based approach for estimating thermophysical properties of fats and vegetable oils for modeling biodiesel production processes, Ind. Eng. Chem. Res. 49 (2) (2010) 3022-3023.

[48] L. Zong, S. Ramanathan, C.-C. Chen, Predicting thermophysical properties of mono- diglycerides with the chemical constituent fragment approach, Ind. Eng. Chem. Res. 49 (11) (2010) 5479-5484.

[49] EN 14214, European Standard EN 14214, Automotive Fuels - Fatty Acid Methyl Esters (FAME) for Diesel Engine - Requirements and Test Methods, CEN - European Committee for Standardization, Brussels, Belgium, 2008.

[50] L.T. Biegler, J.E. Cuthrell, Improved infeasible path optimization for sequential modular simulators - II: the optimization algorithm, Comput. Chem. Eng. 9 (3) (1985) 257-267.

[51] R. Franke, Omuses a tool for the Optimization of multistage systems and HQP a solver for sparse nonlinear optimization, version 1.5, Technical report, Technical University of Ilmenau, Germany, 1998.

[52] A.C. Hindmarsh, P.N. Brown, K.E. Grant, S.L. Lee, R. Serban, D.E. Shumaker, C.S. Woodward, SUNDIALS: suite of nonlinear and differential/algebraic equation solvers, ACM Trans. Math. Softw. 31 (3) (2005) 363-396.

[53] A. Walther, A. Griewank, Getting started with ADOL-C, in: U. Naumann, O. Schenk (Eds.), Combinatorial Scientific Computing, Computational Science, Chapman-Hall CRC, 2012, pp. 181-202, Ch. 7.

[54] E.C. Ihmels, J. Gmehling, Extension and revision of the group contribution method GCVOL for the prediction of pure compound liquid densities, Ind. Eng. Chem. Res. 42 (2) (2003) 408-412.

[55] B.E. Poling, J.M. Prausnitz, J.P. O'Connell, The properties of Gases and Liquids, 5th Edition, McGraw-Hill, New York, 2001.

[56] R. Ceriani, R. Gania, A. Meirelles, Prediction of heat capacities and heats of vaporization of organic liquids by group contribution methods, Fluid Phase Equilib. 283 (1-2) (2009) 49-55.

[57] R.H. Perry, D.W. Green (Eds.), Perry's Chemical Engineers' Handbook, 7th ed., McGraw-Hill, New York, 1997, ch. 2: Specific heats of pure compounds, pp. 2.161-2.185.

[58] M.C. Righetti, G. Salvetti, E. Tombari, Heat capacity of glycerol from 298 to 383 K, Thermochim. Acta 316 (2) (1998) 193-195.

[59] E.S. Domalski, E.D. Hearing, Estimation of the thermodynamic properties of $\mathrm{C}-\mathrm{H}-\mathrm{N}-\mathrm{O}-\mathrm{S}-$ halogen compounds at 298.15 K, J. Phys. Chem. Ref. Data 22 (4) (1993) 805-1139. 